indicated $99.4^{\circ}$; the throat at no time presenting an inflamed appearance. The inflammation in the ragina daily increased, large shreds of false membrane, almost forming complete casts of the vagina, were discharged; asthenia was great; the pulse small and compressible; the pupils were frequently irregular, and responded feebly to light. About this period of the disease the patient (who was five months pregnant) was attacked with well-marked labour pains, occurring at regular intervals. As it was considered that, should a miscarriage take place, the disease would extend to the uterus, with a probably fatal issue, very large doses of opium were given with a view of stopping the uterine contractions, which had the desired result after the patient had taken about five grains of this drug. Under treatment the discharge from the vagina became less, and the development of false membrane decreased till about ten days after its first appearance, when it had entirely disappeared. Convalescence rapidly took place, and the patient, who was removed to the country, was subsequently delivered of a living child, with no bad results.

Treatment.--Carbolic acid combined with quinine was given internally every three hours (each dose containing one minim of carbolic acid, ten minims of glycerine, and one drachm of tincture of quinine, in an ounce of water), the urine being carefully watched during its administration. lodoform was applied locally with vaseline (a drachm to the ounce). When the ragina became affected, it was frequently washed out with a solution of permanganate of potash. Strips of lint soaked in iodoform and vaseline were introduced into the vagina and changed every few hours. Stimulants and strong liquid food were given in large quantities when the asthenia was great.

Remarks.-This is one of several cases I have treated with carbolic acid and quinine given internally in this disease; the results so far have been more satisfactory than any other treatment I have seen tried. The cases in which it has been adopted have, however, been too few as yet to merit more than a suggestion that it is worthy of a more extended trial.

\section{ROISONING BY BENZOLINE VAPOUR.}

By A. G. R. FOULERTON, M.R.C.S., L.R.C.P. RESIDENT MEDICAL OFFICRR, ROYAL ISLE OF WIGHT INFIRMIARY.

PoIsoning by benzoline is of sufficiently rare occurrence to warrant the recording of the following case, in which, however, as will be seen, the effects of the poison may have been complicated to some extent by the high temperature in which the patient was at the same time placed.

W. $\mathbf{S}-$, aged twenty-five, a well-made and healthylooking German, entered a zinc tank used for the storage of benzoline, and then all but empty, at 9 A.M., and at 11 A.M. was found lying insensible at the bottom of it. The tank was some $5 \mathrm{ft} .6$ in. high, with a small man-hole at the top, and exposed to the direct heat of a powerful sun, a thermometer inside registering $105^{\circ} \mathrm{F}$. Shortly afterwards, when the man was brought to the infirmary, I found him in the following condition: Smelling strongly of benzoline; anable to stand, but capable of answering simple questions in an indistinct sort of way; moaning occasionally, and from time to time bursting into a hysterical laugh; face flushed; surface of body and limbs cold and clammy; muscular tremors and twitchings in the legs and arms pupils widely dilated, reacting to a strong light stimulus; pulse 88 , full and soft; respiration from 8 to 9 in the minute, deep and stertorous, irregular in rhythm, as much as iffteen seconds intervening between the separate inspirations; heart's action feeble; temperature in axilla $988^{\circ}$. Shortly after admission he vomited freely, the ejected matters being bile-coloured and smelling of benzoline.

The man was given at once twenty-five minims of solution of ammonia with half a drachm of ether and put to bed, wrapped up in blankets, and hot-water bottles used. He then had half a drachm more of ether with some brandy, and was given frequent half-drachm doses of aromatic spirit of ammonia. For about two hours the patient remained in much the same condition, becoming at times absolutely unconscious, his breathing also getting worse at intervals. At the end of that time he began to improve rapidly, and was soon afterwards able to give a rational account of himself but could not say how long he had been in the tank before he lost consciousness. His pupils were still dilated, and he complained of bad headache. He then had an attack of profuse sweating, and by the evening had completely recovered, no trace of his misadventure remaining beyond some slight headache. The temperature and respiration were normal, and the pulse 76. The urine passed presented nothing extraordinary, and a motion following the administration of half an ounce of castor oil was of a dark-green colour.

From these symptoms it will be seen that benzoline is a well-marked example of an inebriant poison. It was not thought necessary to give an emetic, as the man had merely been exposed to the vapour and had not swallowed any liquid benzoline; he settled the matter, however, by vomiting spontaneously. Theoretically, brandy and ether (being themselves inebriants) would seem to be contra-indicated, but the result was sufficiently satisfactory to justify their use. Looking hack on the case, 1 cannot help thinking that the man might have been further benefited by a little bloodletting, for $I$ regard the main symptoms as pointing to failure of the heart's action, diminished capillary tension, and consequent stagnation in the venous system, with overdistension of the right side of the heart. Were a similar case to occur to me again, I should be content, I think, with the application of external warmth and moderate bleeding and the free use of ammonia.

Ryde.

\section{A}

\section{HOSPITAL PRACTICE, BRITISH AND FOREIGN.}

Nulla autem est alia pro certo noscendi via, nisi quamplurimas et morborum et dissectionum historias, tum aliorum tum proprias collectas habere, et inter se comparare.-MobGaGMI De Sed. et Caus. Morb., lib. iv. Procemium.

\section{UNIVERSITY COLLEGE HOSPITAL.}

SARCOMA OF THE RECTUM; LITTRÉ'S COLOTOMY; RELIEF; REMARTS.

(Under the care of Mr. Antuun E. BAnken.)

THF malignant growth met with in the rectum is almost always the adenoid or cylindrical epithelioma, sometimes undergoing colloid degeneration. Scirrhus and encephaloid are very rare, and it is probable that recorded cases of the latter will become fewer as the microscopical examination of these growths is more regularly conducted, many cases which would otherwise have been classed as encephaloid proving to be of sarcomatous nature when thus examined. The reasons which induced the operator to prefer Littré's operation to that of left lumbar colotomy, which is usually practised when local removal of the growth is impossible, will be found in the remarks appended to the case.

H. A- a a , aged thirty-eight, a labourer, was admitted into University College Hospital on July 29 th, 1886 , on account of diarrhoea alternating with obstruction of the rectum, and severe pain, the result of growth in the bowel. His sufferings began with violent diarrhœa in the previous March, which lasted about two months, and was followed in June by constipation. On straining blood was passed, but pain was not complained of until the end of June. It was then a wellmarked symptom, especially at night and during efforts at defecation, which were usually fruitless.

On admission a large mass of growth could be felt in the rectum, almost completely surrounding the bowel. It was soft and lobulated, and completely blocked the passage. A portion of it, as large as a hen's egg, was broken off with the finger by Mr. Heath on July 30th, and was found on microscopical examination to consist of fibro-sarcoma. Profuse bleeding followed, but was checked by plugging of the rectum. As there seemed no prospect of benefit from any local operation and the patient's sufferings were severe, it was determined to open the colon and establish an artificial anus. This was done by Mr. Barker on Aug. 18th by Littré's method. All antiseptic precautions having been observed, an incision was made from a point just internal to the anterior superior spinous process of the ilium, downwards and inwards for about three inches, terminating about an inch above Poupart s 